\title{
Economic Implications of Non-Timber Forest Products/Benefits/ to Livelihood Improvement in Terms of Income and Determinants of Household Participation in NTFPS Collection: A Case Study of Mecha Woreda, Amhara Region
}

\author{
Addisu Tadesse \\ Department of Environmental and natural resource Economics, Raya University
}

\begin{abstract}
The purpose of this thesis was studying the "economic implications of non-timber forest products/benefits/ to livelihood improvement in terms of income and determinants of household participation in NTFPs collection: a case study of Mecha Woreda, Amhara region". The major sources of data for the study were a well-organized questionnaire distributed over the study site. The secondary data have been gained from the Woreda office of agriculture and rural development and used mainly for description of the study area. Moreover, the study tried to investigate the major NTFPs extracted, their contribution in the form of income, and major determinants of household's decision in participation of NTFPs collection as an objective, via the tool of both descriptive and econometric model analysis in particular. Honey and beeswax, charcoal, fuel wood, and 'Gesho' /Rhamnus prionides/ are most important source of income from among the non-timber forest products. From the descriptive part even if the Woreda is one of the surplus producer area of crop production, households around forests in the study area are considerably dependent on NTFPs by generating nearly $20.17 \%$ of their total income from NTFPs during the study period. Charcoal extraction mainly from plantation forests is primary income producer by contributing around $37.52 \%$ of total income from NTFPs. Honey and bees wax, fuel wood, and Gesho were also contributing $32.68 \%, 25.17 \%$, and $4.31 \%$ of aggregate income from non-timber forest products during the study period respectively. On the other hand, most wild edible plant products including plantation coffee are importantly provides subsistence especially for the children in the study area. The study also found that age, family size, distance to forest, and number of livestock a household possess were the major determining factor in the participation of NTFPs extraction. Households who are far from the forest, own large amount of livestock, and being aged were less likely to participate in the collection of non-timber forest products, while those who have relatively large amount of family member were more likely to participate in NTFPs collection. Even if it needs further investigation, it seems reasonable that the likelihood of household's participation decrements and increments as amount of livestock owned increases and number of family member increases is due to the availability of alternative source of income from livestock and labor from family members for NTFPs collection respectively.
\end{abstract}

Keywords: NTFPs, livelihood improvement, income, Mecha Woreda

DOI: $10.7176 / \mathrm{JESD} / 10-1-06$

\section{Introduction}

Forests in general and NTFPs in particular, are the center of human survival since we inhabited the planet earth. However, the importance and valuation of forests at a particular place and time depends hugely on their scarcity or abundance relative to changing human needs (Joshua, 1998).

Forests in the form of timber and non-timber benefits served the human society since the creation and inhabitation of our planet. For example, nowadays some 800 million people of the world live in or near tropical forests and savannas, and depend on these ecosystems and their services and welfare benefits for fuel, food and income (Schaafsma et al, 2013). From this number some 250 million people live in dry forests of Sub-Saharan Africa including Ethiopia, and most of them depend on the forests for building materials, food, cropland, fuel wood, non-wood product and many other things (Abebe and Steven, 2011).

Economic activities which are forest-based in developing countries, mostly in NTFPs area, provide nearly 17 million full-time jobs in the formal sector and some 30 million employments in the informal sector, and between 13-35\% of all rural non-farm employment as well (Ahmed, 2013).

For instance, Ethiopia owns diverse vegetation resources that include high forests, woodlands, bush lands, plantations, and trees outside forests. Each of these vegetation resources variously contributes to the production, protection and conservation functions, and play significant role in the national and local economy.

Despite their usefulness for human survival, forests are nowadays extensively removed, in different parts of the world especially in the developing countries. According to Million (2011) the forest cover of Ethiopia due to intense afforestation reaches 12.3 million ha or $11.9 \%$ of the total land area some projected it at $15 \%$ in 2015 from less than $3 \%$ in the late 1990 s compared to around $30 \%$ at the end of the $19^{\text {th }}$ century (Sara, 2015).

Mulugeta et al (2015) stated that the possible reasons of deforestation could be poorly defined forest 
property rights and insecurity of tenure. Furthermore, weak policy implementation on land use, low capacity of forest institutions, land use conflicts and Policy discrepancy are adding the fuel to the problem of forest loss (Abraha, 2015)

\section{Historical Use of NTFPs in Ethiopia and the study area}

For as long as people have lived in the world, NTFPs have contributed greatly to the livelihoods and well-being of human beings. Unlike today, in times when obtaining food was not as easy as going to the store, wild plants were important sources of nutrition. Due to its varied ecological and climatic conditions, Ethiopia is home to some of the most Diverse flora and fauna in Africa. NTFPs in Ethiopia cover a wide range of products and are most extensively used to supplement diet and house hold income, notably during particular seasons in the year, and to help meet medicinal needs as well (Solomon, 2016). The most important NTFPs in Ethiopia include coffee; spices and condiments; honey and wax; bamboo; reeds; natural gums such as gum Arabic, frankincense and myrrh; edible plant products like leaves and shoots, fruits, seeds, tubers, mushrooms, edible oil, and fat; fodder; fibers; bark, simple sugar products; essential oils; tannins and dyes; resins; latex; ornamental plants and giant grasses etc...

They are largely important for subsistence and economic buffer in hard times. These products contribute to the improvement of the livelihoods of rural communities by providing food, medicine, additional income, and employment opportunities and foreign exchange earnings of the country. In addition, by complementing woodbased management, they offer a basis for managing forests in a more sustainable way (Solomon, 2016).

Regarding energy the most significant use of forests in Ethiopia in both volume and value terms is in the form of fuel wood. Ethiopia is highly dependent on biomass for producing energy. Fuel wood consumption in 2000 was estimated at 98,985,000 m3. This makes for an industry worth approximately USD 420 million per year (Abebe et al, 2009).

Only a few NTFPs produced in Ethiopia have export value. The most important of these is coffee. Over 80 per cent of exported coffee is grown in small gardens or wild in the forest (Abebe et al, 2009). MoARD reported in 2005 that Ethiopia exported coffee worth over USD 200 million (Matchmaker, 2006). In addition, 2,720 tons of gum resin was exported in 2003 with a value of USD 4,128,165. This product was harvested from the 2,855,000 ha of forests that contain gum resin tree species (Wubalem et al, 2007, Abebe et al, 2009).

Other economically significant NTFPs include bamboo, honey and beeswax. Bamboo is a particularly important construction material in the lowlands, where few alternatives exist. Lowland bamboo (Oxytenanthera abyssinica) is utilized for pulp and paper production while highland bamboo (Yushania alpina) is favored for furniture making and other crafts (Kassahun, 2000, Abebe et al, 2009).

Ethiopia has $67 \%$ of Africa's bamboo resources which is about $7 \%$ of the world total. It has about 1 million ha of highland bamboo. Arundinaria alpina accounts 150, 000 ha, out of which 130, 000 ha is natural and 20, 000 ha human made bamboo plantations owned by framers. Lowland bamboo is dominant with coverage of 700,000-850,000 ha. Bamboo provides food, fodder, furniture and building materials (scaffoldings), industrial inputs, medicinal plants and fuel. Solid bamboo has been tested as a concrete reinforcement to substitute steel and the results have revealed success (Solomon, 2016).

(Vivero, 2001) beekeeping is an ancient tradition in Ethiopia with an annual production of about 24,000 tons of honey. This is a third of the total honey production in Africa. The density of hives is estimated to be the highest in Africa. An estimated 4-10 million traditional beehives and some 10, 000 modern boxes exist in the country. (FAO, 2005) puts Ethiopia as the largest honey producer in Africa $(24 \%)$ and the 9th in the world. However, (Chowdhury et al, 2005) stated that Ethiopia is the leading producer of honey in Africa and the tenth largest producer in the world by an estimated some 26,000 tons of honey per year. The main products of the beekeeping industry are honey and wax (Solomon, 2016). Honey is almost exclusively consumed locally especially to make mead, local alcoholic drink made by fermenting honey with water i.e. Tej. While a considerable proportion of wax is exported. Traditional hives are the mainstay of honey production until recently, but they are backward, time-consuming to construct and give low yields compared to the modern way of production (Abebe et al, 2009).

Therefore apart from social and ecological importances the overall economic contribution of NTFPs in Ethiopia is significant, diversified and valuable. The NTFPs are among the main coping mechanisms that poor households and the nation have (Solomon, 2016). Thus, their importance deserves proper management.

\section{Methodology}

\subsection{Study area}

The study was conducted in Mecha Woreda, Amhara region north western Ethiopia. The Woreda is one of the 15 Woredas in West Gojjam administrative zone of Amhara region. It is located 35 kilometers away from the regional capital town Bahir Dar and 534 kilometers away from Addis Ababa the capital city on the main high way from Addis Ababa to Bahir dar. It is bordered by North Achefer Woreda and Bahir Dar Zuria Woreda in 
the North, Sekela Woreda and Awi zone in the South, south Achefer in the west, and Yilmana Densa Woreda in the east. Absolute location of the Woreda is situated between $11^{\circ} 10^{\prime} 00^{\prime \prime}-11^{\circ} 30^{\prime} 0^{\prime \prime}$ N latitude and $37^{\circ} 0^{\prime} 0^{\prime \prime}-38^{\circ}$ 20' 0' E longitudes.

The Woreda is one of the largest Woreda in the administration zone covering a total area of 156,027 hectares of land. From this about 119,927 hectares of land $(76.8 \%)$ is plane, 12,791 hectares $(8.2 \%)$ is mountainous, 6,369 hectares (4.2\%) valley, and others cover 16914 hectares $(10.8 \%)$ of land. Currently, the land use pattern shows that out of total area of the Woreda 72138 hectares of land is cultivable and suitable for crop production and the remaining land is used for grazing 14723 hectares, covered by forests 21553.5 hectares, 6517 hectares for settlement, 14418.88 hectares for irrigation purpose, and the rest 26676.62 hectares of land is covered by others (water, swamps, ponds, valleys and others).

The climatic composition reveals that $80 \%$ of the Woreda is 'woina dega' and the remaining $20 \%$ is 'dega'. The altitude ranges from 1800-2500 meters above sea level and the major source of rain is the summer season rain and annual average rain fall ranges from $1500-2000$ millimeter.

Regarding soil composition red soil is the dominant soil type in the area and covers nearly $93 \%$, brown soil and black soil covers $4 \%$, and $3 \%$ of the total soil type respectively.

\subsection{Sampling method and sample size determination process}

In this study both probability and non-probability sampling technique were employed in the process of sample size determination. Sample refers to the number of people or things taken from a large group and used in tests to provide information about the group, and sampling is the process of selecting a sample from a given population (Kothari, 2004). Population on the other hand, refers to the entire set of relevant units' targeted by the study. In this regard the targeted population in this study was the household residence of Mecha Woreda.

Therefore, the study used different types of sampling techniques in the process of determining the representative sample size for this study. Some of the techniques employed here in the study were; purposive and simple random sampling techniques. The former technique which is non probabilistic in nature used in the determination of potential Kebeles in NTFPs production in Mecha Woreda, and the latter method /probabilistic/ applied in the selection of households that were surveyed.

Depending on preliminary survey, potential NTFP Kebeles were identified and specific survey Kebeles were selected. Out of 40 Kebeles in the study area, twelve Kebeles were identified as the potential area of NTFPs production and collection. And, from this potential Kebeles 3 were purposively selected based on availability of NTFPs and the researcher assumed the selected Kebeles were a good representative. Therefore, the total sample size in the study was determined by using the commonly used rule of thumb technique which states the possible minimum sample size should be $\mathrm{N} \geq 50+8 \mathrm{~m}$, where ' $\mathrm{N}$ ' is minimum number of households surveyed and ' $\mathrm{m}$ ' is the number of explanatory variables used in the econometric model (Green, 1991 cited in Ermias, 2011; and Tofic, 2012). The independent variables planned to be used in this study were ten with which the applied rule of thumb suggests the minimum sample size to be $130(\mathrm{~N} \geq 50+8 \times 10 \geq 130)$. Consequently, a total of 160 households were randomly selected from the three selected survey Kebeles.

Moreover, the number of households surveyed across the sample Kebeles was proportional to the total number of farm households residing in the respective Kebeles; therefore all the sampling units over the survey Kebeles have equal chance of being selected.

\subsection{Sources of data and method of data collection}

A series of primary and secondary data were collected for the study. Primary data was collected mainly from a household survey via using a well-organized questionnaire over the study site. On the other hand, Secondary data was gained from the respective office of the woredas agriculture and rural development and typically used for the description of the study area and used as an input in the selection of potential Kebeles in NTFPs production over the study area.

In the household survey, a well-organized questionnaire was prepared and was distributed over the study area. Based on the time of extraction of NTFPs by an individual household, the production year was divided into four locally identified seasons to describe the patterns of livelihood activities in the study site.

The questionnaire included questions about households' socio-economic and demographic characteristics, households' major assets, households' collection and marketing of and annual revenue from NTFPs, and households' annual incomes from the different income sources other than NTFPs.

\subsection{Econometric model specification and method of data presentation}

In fulfilling the objectives of the study, both descriptive and econometric analyses were used. The collected data all over the survey was checked carefully. During the data checking 12 questionnaires were found incomplete and removed from data processing and analysis. Then, the data processing was done with the remaining 148 questionnaires collected over the study site. 
Depending on the nature of NTFPs in the study area concerning their contribution to the household; the study incorporates both subsistence and cash income contributions. Therefore, the calculation of income, from households' collection of NTFPs, involved the use of market/actual and shadow prices. Household income from NTFPs extraction were calculated using actual market prices if the product is traded in the market, for example honey and beeswax products and shadow pricing method was employed when the product had no market price, for instance, most WEPs in the study area have no clear cut market prices.

And in estimating the net income of the household from NTFPs collection all costs for material inputs, transportation cost to the market place, and other expenses were deducted from the gross household income.

In order to accomplish the first two specific objectives descriptive analysis method using STATA version 12.0 was employed. In doing so, descriptive statistics, like means, ratios, frequencies, and others were employed to investigate major NTFPs and assess their economic contributions both in the form of subsistence and cash income to household livelihood improvement in the study site. Regarding the third specific objective of the study an appropriate econometric analysis was employed to analyze the determinants of household participation in the extraction of NTFPs in the research site. Therefore, due to the dichotomous nature of the objective a binary logistic regression was used to analyze factors that determine a household's participation in NTFPs extraction.

There are many economic relationship theories in which the dependent variable is qualitative in nature. In an attempt to study this type of economic relationships econometricians developed a series of qualitative response regression models in the course of their study. The explained variable may be dichotomous/binary/, trichotomous, polychotomous/multi-categorical/, ordinal or still nominal i.e. no clear cut ordering naturally (Gujarati, 2004). To study binary outcomes just like in this research there are a number of discrete choice models that can be used. For instance, LPM, binary logit and probit, weibull models and the like are available.

Each model has its own merits and demerits over the other. For instance, the LPM has a series of shortcomings compared to the logit and probit models. For example; the error term is not normally distributed around its mean, hetroscedasity nature of its variance, relatively small value of goodness of fit relative to the other models under discussion, and most importantly there is no guarantee for the fulfillment of the condition $0 \leq$ $E(Y i \mid X) \leq 1$ i.e. the probabilities are not necessarily bounded between 0 and 1 . Even if it is possible to overcome these problems using different techniques in the model, it is worth using other sustainable models than dealing with LPM.

Therefore, to overcome such a problem researchers restrained from using this model and turning their face to the alternative discrete choice models such as logit and probit. These two models can guarantee the above demerits not happen. One can employ either logit or probit models in the analysis of some economic theories, but in this research due to its mathematical convenience the researcher employed binary logit model to deal with determinants of household participation in the extraction of NTFPs over the study area.

Thus, in the logistic regression analysis, determinants of participation in the extraction of NTFPs were estimated. The logistic distribution function for identification of the participant and non-participant households of major NTFPs collection can be defined as:

$P i=E(Y=1 \mid X i)=\frac{1}{1+e^{-z_{i}}}$

And for simplicity multiplying this expression by the ratio $\frac{e^{z_{i}}}{e^{z_{i}}}$ yields the logistic distribution function of the form:

$$
P_{i=} \frac{e^{z_{i}}}{1+e^{z_{i}}}
$$

Where,

$P_{i}$ is the probability of being participant in NTFPs collection and marketing for the $\mathrm{i}^{\text {th }}$ observation, $Z_{i}$ is a set of socioeconomic factors affecting participation $\left(X_{i}\right)$ and the stochastic term $\left(U_{i}\right)$ expressed as:

$$
n
$$

$$
\mathrm{Z}_{\mathrm{i}}=\beta_{\mathrm{o}}+\quad \beta_{\mathrm{i}} \mathrm{x}_{\mathrm{i}}+\mathrm{u}_{\mathrm{i}}
$$

1

Where;

$\beta 0$ is the intercept term,

$\beta i$ are the slope parameters or coefficients of determination in the model, and $\mathrm{n}$ is the number of explanatory variables.

In the linear regression model, the slope parameters measures the change in the average value of the regressand for a unit change in the value of a regressor, with all other variables held constant. Put it in another way, slope coefficients in the linear regression models measures the marginal effect of explanatory variables on the explained variable in a citrus paribus situation.

But in the tradition of binary models the situation is somewhat different; because, the marginal effects 
depend on the value of each explanatory variable in the model and we don't know what values of the explanatory variable in calculating the marginal effects. Therefore, there are two possible ways of calculating the marginal effects on the probabilities of each independent variable. The first possible way is evaluating the marginal effects using the mean values of each elements of the explanatory variable. This is marginal effects at the mean and very tiresome. The second possible way of computing marginal effects is evaluating the mean of the marginal effects itself (Ricardo, 2009).

Therefore, mean marginal effect of continuous variables can be calculated as:

$$
\frac{\partial \underline{\operatorname{Pr}(\mathrm{y}=1 \mid \mathrm{x})}}{\partial x_{\mathrm{j}}}=\frac{\partial \underline{\operatorname{Pr}(\mathrm{y}=1 \mid \mathrm{x})}}{\partial x \beta} \cdot \frac{\partial x \beta}{\partial x_{\mathrm{j}}}=\eta(\mathrm{x} \beta) \cdot \beta \mathrm{j}
$$

On the other hand, marginal effect of the categorical variables can be computed as:

Marginal Effect $\mathrm{x}_{\mathrm{j}}=\operatorname{Pr}\left(\mathrm{y}=1 \mid \mathrm{x}, \mathrm{x}_{\mathrm{j}}=1\right)-\operatorname{Pr}\left(\mathrm{y}=1 \mid \mathrm{x}, \mathrm{x}_{\mathrm{j}}=0\right)$

There is no "right" or "wrong" way to evaluate the marginal effects. The important thing is to give the right econometric interpretation for the strategy chosen (Ricardo, 2009).

Therefore, the general economic model for determinants of household participation in NTFPs collection is as follows.

$\mathrm{Y}=f(\mathrm{SEX}, \mathrm{AGE}, \mathrm{FAMSIZE}$, DISTOWN, DISFOREST, LIVESTOCK, EDUCATION, MARRIAGE,

LANDSIZE, NFARMINC)

After specifying an economic model, we should turn it into what we call an Econometric model.

$\mathrm{Y}=\beta_{\mathrm{o}}+\beta_{1} \mathrm{D}_{1}+\beta_{2}$ age $+\beta_{3}$ famsize $+\beta_{4}$ distown $+\beta_{5}$ disforest $+\beta_{6}$ lstock $+\beta_{7} \mathrm{D}_{2}+\beta_{8} \mathrm{D}_{3}+\beta_{9}$ lsize $+\beta_{10} \mathrm{D}_{4}+$ $\mathrm{u}_{\mathrm{i}}$

Where;

\section{Explained variable}

$\mathrm{Y}$ is a binary response explained variable, $\mathrm{Y}=1$ if participated

$$
\mathrm{Y}=0 \text { otherwise }
$$

\section{$\checkmark \quad$ Explanatory variables}

$\mathrm{D}_{1}$ is dummy variable representing gender of a household head, 1 if male

$$
0 \text { otherwise }
$$

age $=$ is a continuous variable denoting age of the household head

famsize $=$ a continuous variable number of household member measured in numbers

distown $=$ is a continuous variable of distance from town measured in walking hours

disforest $=$ a continuous variable of distance from the forest measured in walking hours

lstock $=$ is a continuous variable representing the number of livestock a household possess in tlu

D2 = is dummy variable representing education level of household head, 1 if basic education

$$
0 \text { otherwise }
$$

D3 = is a dummy variable representing marital status of the household head, 1 if married

lsize $=$ total size of land a household possess in hectares

0 otherwise

D4 = is dummy variable representing income from non-farm activities, 1 if available

$u i=$ the error term in the model

0 otherwise

\section{Result and Analysis}

\subsection{Major NTFPS extracted and their contributions in the form of additional income}

Non-timber forest products were extracted for different purposes in the study area. Some of the NTFPs were extracted for own consumption /subsistence/ and others were collected for commercial /income generation/ purposes. In this regard honey and beeswax production, fuel wood, and charcoal extraction, were the most widely practiced economic activities in income generation which are forest based other than timber in the study site. Moreover, Gesho and bamboo collection were also generated significant amount of income for the sampled households. But, the importance of these activities was inclined towards own consumption rather than commercial purpose. 
Table 4.5 Major NTFPs extracted in the study area and their total and mean annual income contribution

\begin{tabular}{lcccc}
\hline NTFPs & N & Total income(birr) & Average income(birr) & Contribution (\%) \\
Honey and beeswax & 60 & 236535 & 3942.25 & $32.68 \%$ \\
Charcoal extraction & 80 & 271597 & 3394.96 & $37.52 \%$ \\
Gesho/Rhamnus prionides/ & 55 & 31223 & 567.69 & $4.31 \%$ \\
Bamboo & 14 & 2319 & 165.64 & $0.32 \%$ \\
Fuel wood & 30 & 182212 & 6073.73 & $25.17 \%$ \\
\hline \hline Total & 239 & 723886 & 3028.81 & $100 \%$ \\
\hline Source: Stata result 2017
\end{tabular}

Source: Stata result, 2017

Charcoal extraction was the widely practiced and among the highest average and aggregate income contributor from the NTFPs extracted over the study area. During the study period among the sampled households' 80 households $(54.05 \%)$ of the respondents found to be practiced charcoal extraction. Its crude aggregate income was ETB 271597 per annum. And the mean income from this non timber forest product was ETB 3394.96 per household participating in the extraction of it and covers $37.52 \%$ of total income that NTFPs contributed in the study area annually. These shows that the highest proportion of income contribution from nontimber forest products mainly emanating from charcoal extraction during the study period (see table 4.5). Moreover, $74.68 \%$ of the production was sold to local traders and the remaining $25.32 \%$ directly delivered to the consumers and mainly traded $83.33 \%$ by husbands.

\subsection{Estimation of logistic regression model and analysis}

\subsubsection{Determinants of household participation in extraction of NTFPs}

Out of the ten explanatory variables in the fitted robust logistic model, four variables were significant at the usual 5\% level of significance (Table 4.10). The Wald chi square of 33.30 with a p-value of 0.0002 tells us that our model as a whole is statistically significant at 5\% level of confidence, as compared to the null model with no predictors. The pseudo $\mathrm{R}$ squared of 0.3292 also shows that $32.92 \%$ of the independent variable is correctly explained by the explanatory variables included in the model. The significant explanatory variables in the fitted model were age, family size, distance to forest, number of live stocks in tlu.

\subsubsection{Marginal effects after logistic regression}

Marginal effects can be an informative means for summarizing how change in a dependent variable is related to change in explanatory variable. For categorical variables, the effects of discrete changes are computed, i.e., the marginal effects for categorical variables show how $\mathrm{P}(\mathrm{Y}=1)$ is predicted to change as a binary covariate changes from 0 to 1 holding all other variables equal. This can be quite useful, informative, and easy to understand. For continuous independent variables, the marginal effect measures the instantaneous rate of change. If the instantaneous rate of change is similar to the change in $\mathrm{P}(\mathrm{Y}=1)$ as the explanatory variable increases by one, this too can be quite useful and intuitive.

Marginal effects are also called instantaneous rates of change; we can compute them for a variable while all other variables are held constant. The magnitude of the marginal effect depends on the values of the other variables and their coefficients in non linear regressions. The Marginal Effect at the Mean (MEM) is popular (i.e. compute the marginal effects when all other explanatory variables are at their mean) but many think that Average Marginal Effects (AMEs) are superior. Therefore, in this study average marginal effects were calculated and interpreted. In this study the researcher used the command 'margins' instead of the outdated 'mfx' command to get the average marginal effect of each covariate.

Thus, a one year increase in the age of the respondents decreases the probability of the respondents being participant in the collection of the NTFPs by $1.4 \%$. On the other hand, a one person increase in the member of the household increases the probability of the household's participation in the extraction of non timber forest products by $7.4 \%$. Distance to forest has a negative relationship with likelihood of participation and an increment of one walking hour to the forest decreases the probability of household's participation in the collection of NTFPs by $9.9 \%$. Likewise, the probability of the participation in NTFPs extraction of household's decreases by $3.5 \%$ as a result of a unit increase in the number of lives tocks in tlu. Landsize on the other hand, has an almost significant positive effect on the probability of household's participation in NTFPs collection. 


\section{Conclusion}

Generally, in this study the researcher tried to analyze the economic implications of non-timber forest products to livelihood improvement in Mecha Woreda. Moreover, the study tried to investigate the major NTFPs extracted, their contribution in the form of income, and major determinants of household's decision in participation of NTFPs collection as an objective, via the tool of both descriptive and econometric model analysis in particular.

Honey and beeswax, charcoal, fuel wood, and Gesho are most important source of income from among the non timber forest products. From the descriptive part even if the Woreda is one of the surplus producer area of crop production, households around forests in the study area are considerably dependent on NTFPs by generating nearly $20.17 \%$ of their total income from NTFPs during the study period.

Charcoal extraction mainly from plantation forests is primary income producer by contributing around $37.52 \%$ of total income from NTFPs. Honey and bees wax, fuel wood, and Gesho were also contributing 32.68\%, $25.17 \%$, and $4.31 \%$ of aggregate income from non-timber forest products during the study period respectively.

Most wild edible plant products including plantation coffee are importantly provides subsistence especially for the children in the study area.

The study also found that age, family size, distance to forest, and number of livestock a household possess were the major determining factors in the participation of NTFPs extraction. Households who are far from the forest, own large amount of livestock, and being aged were less likely to participate in the collection of nontimber forest products, while those who have relatively large amount of family member were more likely to participate in NTFPs collection. Though, it needs further investigation, it seems reasonable that the likelihood of household's participation decrements and increments as amount of livestock owned increases and number of family member increases due to the availability of alternative source of income from livestock and labor from family members for NTFPs collection respectively.

\section{References}

Abebe, D. \& Steven, F. K., (2011) Non-Timber Forest Products Dependence, Property Rights and Local Level Institutions: Empirical Evidence from Ethiopia; University of Pretoria.

Abebe, H. G., Million, B., \& Ridgewell, A. (2009) Small and medium forest enterprises in Ethiopia: IIED Small and Medium Forest Enterprise Series No. 26.

Abraha, H., (2015) Trend of forest cover change in Ethiopia: Georg -August Universität Göttingen South Africa.

Ahmed, M. (2013) Contribution of Non-timber Forest Products to Household Food Security: The Case of Yabelo Woreda, Borana Zone, Ethiopia; Food Science and Quality Management www.iiste.org ISSN 22246088 (Paper) ISSN 2225-0557 (Online) Vol.20, 2013

Chowdhury, Q., van de Graaf, R., Hazenberg, S., Erniwati, E., Maris, W. \& Paulos, T. (2005) Poverty alleviation through NTFP development in S-W Ethiopia: Options for certification of coffee and honey for poverty alleviation and forest conservation, Student Research Series No. 2. Wageningen.

Gujarati, N. D (2004) basic econometrics: the McGraw- hill companies.

Habtemariam K., Berihun T., \& Girmay F. (2011) Preliminary value chain analysis of gum and resin marketing in Ethiopia: Issues for policy and research; Center for International Forestry Research No. 4, March 2011.

Joshua, T. (1998) the Economics of Non-Timber Forest Benefits, international institute for environment and development environmental economics programme; Environmental Economics Programme IIED 3 Endsleigh Street London WC1H 0DD UK.

Kassahun, E. (2000) the endogenous bamboo forests of Ethiopia: an overview; royal Swedish academy of sciences. A Journal of the Human Environment 29(8):518-521. 2000 doi: http://dx.doi.org/10.1579/0044$7447-29.8 .518$

Kothari, C.R. (2004) research methodology methods and techniques: new age international

Million, B. (2011) forest plantations and woodlots in Ethiopia: African forest forum working paper series.

Mulugeta, L. Claire, A. and Yvan, B. (2015) making forest conservation benefit local communities: participatory forest management in Ethiopia.

Ricardo, N. T. (2009) applied econometrics using Stata: department of economics, Harvard University.

Sara, Sh. (2015) Restoring Ethiopia's forestland at a historic pace:

Schaafsma, M., Jones, S. M., Posen, P.... Turner, R. K. (2013) the importance of local forest benefits: Economic valuation of Non-Timber Forest Products in the Eastern Arc Mountains in Tanzania; Global Environmental Change 24 (2014) 295-305.

Solomon, M. M. (2016) Importance of Non Timber Forest Production in Sustainable Forest Management and Its Implication on Carbon Storage and Biodiversity Conservation in Case of Ethiopia: J Biodiversity Endanger Species 4: 160. doi:10.4172/2332-2543.1000160.

Vivero, J. L. (2001) the role of forest resources in non-farm activities for rural livelihood diversification in Ethiopia: Annual Conference of the Biological Society of Ethiopia: "Imperative Problems associated with 
Forestry in Ethiopia" February, 1-3, 2001, At Addis Ababa, Ethiopia

Wubalem, T. Desalegn G. \& Alia R. (2007) Natural gum and resin bearing species of Ethiopia and their potential applications: Ethiopian Institute of Agricultural Research. Forestry Research Center; P.O. Box 30708, Addis Ababa, Ethiopia 